\title{
Exploring the Politico-Cultural Dimensions for Development of Smart Cities in India
}

\author{
Dillip Kumar Das ${ }^{1 *}$ \\ 1 Department of Civil Engineering, Central University of Technology \\ * Corresponding Author, Email: ddas@cut.ac.za
}

Keywords: Cultural theory, Environmental challenge, Socio-economic challenges, Smart city, Urban governance

\begin{abstract}
Indian cities seem to be in transition regardless of the various sustainability challenges they have experienced in recent years. Globalization, market economy, and technological developments have brought economic, social and infrastructural advantages. However, population growth, proliferation of urban functions, insurmountable increase in size of cities, and environmental crises because of climate change have caused the cities to experience severe spatial, infrastructural and environmental ailments. Besides, the significant rise of Information Communication Technology (ICT) industries in the cities and their socio-economic and spatial influence have brought about inequitable development. At this juncture emancipation of a political will to build smart cities in India provides a new impetus for changing the planning perspectives and warrants a politico-cultural discourse to examine the prerequisites and paradigms, which could aid in development of smart cities in India. Drawing upon the stimulating mix of past experiences and prospective approaches across the world and discussions with experts in the political science, local governance and urban development, this explorative paper provides a discourse on the concept of smart cities, opportunities, challenges and the way forward to realize the goals of smart city development in a heterogeneous but democratically unified country like India. Based on the discourse, it is argued that the current urban governance system is not congruent for development of smart cities in India. Therefore, it is advocated that a cultural theory inspired politico-cultural mechanism be explored and crafted to assemble the requisite elements of an urban governance system that should enable the dynamics and cohesion needed for developing smart cities in India.
\end{abstract}

\section{INTRODUCTION}

The majority of Indian cities seem to be in transition because of the changes in global economic and technological scenarios. Certain phenomena like globalization, adoption of market economy, and technological developments - particularly in the Information Communication Technology (ICT) sector and the consequent shifting in the industrial economic scenarios (like ICT and service industry that have become more predominant than conventional industries) - have brought some economic, social and infrastructural advantages to the cities. Concurrently however, severe sustainability challenges have been experienced. For example, huge population, proliferation of urban functions, insurmountable increase in size 
of cities, and environmental crises have made the cities experience severe spatial, infrastructural and environmental ailments. There is a growing concern among the common men and professionals alike whether the cities of India will remain functional and contribute effectively to the socioeconomic development of the country or degenerate and bring misery to people $^{1}$. At this juncture, emancipation of a strong political will to build smart cities in India offers new challenges to planners and as such provides impetus to change the planning perspectives.

Urban development is considered by many as mostly a physical and spatial challenge, although some also combine it to a certain extent with wider socio-economic challenges (Stone, Clarence N, 1993; Todes, 2011). Although, it is equally a political (Peterson, 1981; Mollenkopf, 1983; Ward, 1996) and a cultural issue (García, 2004), such aspects are undermined in a large and diverse country such as India. The urban planning process in the country largely focuses on the technical and spatial challenges conducted by the professionals under the tutelage of decision makers, despite the provision of stakeholders' engagement and participation, which remains mostly marginal ${ }^{2}$. Moreover, the democratic setup of governance has offered a political platform, which is perhaps the single most dominating factor that decides the fates of cities in India. The mammoth diversity that exists in the country in the form of race, religion, caste, class and socio-economic inequality, varied culture, etc., adds another dimension to the challenges. Thus, it is argued that the political and cultural issues cannot be ignored while deciding new paradigms and evolving policy interventions for the development of urban areas - particularly smart cities in the country. Thus, this scenario warrants a politico-cultural discourse to examine the prerequisites and paradigms, which could aid in development of smart cities in India. Therefore, the objective of this explorative paper is to examine the challenges of smart city development in India; and to proffer a politicocultural discourse for engagement and participation of different social solidarities to realize the goals of smart city development in a heterogeneous but democratically unified country like India. In other words, it focuses on mapping the politico-cultural participative approach as the basis of planning smart cities in India. The article follows an explorative discourse, drawing upon a mix of past experiences and prospective approaches across the world available in the literature as well as discussion with experts and stakeholders engaged in the field of urban development, political science and local governance. Based on the discourse, it is argued that the rationale behind developing smart cities in India is not explicitly defined - and the current social and morphological characteristics of the cities as well as the governance system for development of cities are not congruent for development of smart cities in India. However, a cultural theory inspired programme may be explored and crafted to assemble the requisite elements of an urban governance system that should enable the dynamics and cohesion needed for developing smart cities in India, which could also help in achieving long term sustainability of such cities.

\footnotetext{
${ }^{1}$ View of urban development professionals and people who participated in the survey

${ }^{2}$ View of urban development professionals and political experts
} 


\section{THEORETICAL PERSPECTIVE OF SMART CITIES}

'Smart cities' is a relatively recent concept which appeared small but gradually loomed larger - as affirmed by Townsend (2013) in the epilogue of his book 'Smart Cities: Big Data, Civic Hackers, and the Quest for a New Utopia'. Moreover, it has found more rhetoric in the academic literature on urban sustainability in recent years (De Jong et al., 2015). It has become one of the most popular formulations for the future city, and is becoming a globally recognized term, displacing 'sustainable cities' or 'digital cities' as the word of choice (Moir, Moonen, \& Clark, 2014). However, scholars argue that it has been around for a long time - since the 1980s - although known in different ways such as 'wired cities' (Batty, 2015; Martin, 1978). The smart city has no unequivocal definitions; different schools of thought and different approaches to build such cities have emerged. For example, in South Korea a smart city - Songdo - is developed to foster sustainable design practices through incorporation of the latest technologies that reduce energy consumption and increase energy efficiency, utilize recycled and natural materials and generate clean or renewable electricity (www.songdo.com). Another city, PlanIT valley in Portugal, is developed to combine intelligent buildings, transport, built environment information and energy systems with enhanced mobility, parking and emergency services (Cavada, Hunt, \& Rogers, 2014); Living-PlanIT-SA, 2013). Similarly, Dholera in India was planned or being developed with a perception of seamless integration of urban planning with digital technologies being the most sustainable solution to rapid urbanization in India, which promises to be a new city without the annoyance of everyday urban life (Datta, 2015).

On the other hand, some scholars perceive a smart city in a more systemic way. To them, for example, it is a concept that is derived from the combination of concepts of the Connected city (smart logistics and sustainable mobility), the Entrepreneurial city (economic vitality), the Pioneer city (social participation and social capital), and the Liveable city (ecological sustainability) (Nijkamp \& Kourtik, 2011). A smart city is not considered in a holistic manner, rather with reference to various aspects which range from ICT (Digital) districts to smart populace in terms of educational level (Giffinger et al., 2007; Komninos, 2002; Lombardi, 2011; Shapiro, 2005). It has certain characteristics such as smart economy, smart people, smart mobility, smart governance, smart environment and smart living, which are measured by a set of indicators (Das \& Emuze, 2014; Giffinger et al., 2007).

Besides, Townsend (2013) argued that a smart city is not just a seamless web of integrated and joined-up technologies - which it probably never will be, but it is rather where information technology is combined with infrastructure, architecture, everyday objects and humans to address social and economic problems as well as the environment to create more liveable, functional and equitable cities (Batty, 2015; Datta, 2015; Townsend, 2013). Scholars like Kitchin (2014) see it as a city that is increasingly composed of and monitored by pervasive and ubiquitous computing as well as its economy and governance being driven by innovation, creativity and entrepreneurship enacted by smart people (Kitchin, 2014). Thus, essentially, smart cities are composed of technologies (being referred to as 'everyware') which are ubiquitous computing and digitally instrumented devices built into the very fabric of urban environments, that monitor, manage and regulate 
city flow and processes; engage with place, activities and people - often in real-time (Greenfield, 2006; Hollands, 2008; Kitchin, 2014) and enhance efficiency and sustainability (Hancke, de Carvalho e Silva, \& Hancke Jr., 2013; Townsend, 2013). Furthermore, it is argued that the rich seams of data extracted from these technologies can be used to depict, model and predict urban processes and simulate the possible outcomes of future urban development (Batty et al., 2012; Schaffers et al., 2011). It also supports infrastructure for business activity and growth and it stimulates new forms of entrepreneurship, especially with respect to service- and knowledge economy (Kourtit, Nijkamp, \& Arribas, 2012). The economy and governance are driven by innovation, creativity, entrepreneurship and smart people (Kitchin, 2014). In other words, it has a business-led urban development and a neoliberal approach to governance (Batty, 2015; Deakin, 2014; Hollands, 2008); a focus on the social and human dimensions of the city (Florida, 2005; Hollands, 2008); an adoption of a smarter community's agenda with programmes aimed at social learning, education and social capital (Hollands, 2008); and a focus on social and environmental sustainability (Deakin, 2014; Hollands, 2008). Thus, although not limited to a congenial environment, a smart city offers economic opportunities and entrepreneurial endeavors; uses information and communication technology (ICT) as well as innovation to improve quality of life; provides a safe, efficient and emission free mobility system; possesses an education system and facilities to support research and innovation; possesses an appropriate health care delivery system; and has a responsive governance system as evidenced from various cities in North America and Europe (Cohen, 2013; Mercer Study, 2014; Picon, 2015).

As it stands in the Indian context, it provides two different pathways for development of smart cities. On one hand, it is envisaged to build cities like Dholera, which can be understood as a socio-technical manifestation of an urban utopia or an extension of a postcolonial modernization project with an aim to build new competitive global cities (or knowledge cities, IT Hubs, eco-cities, etc.) from the ground up with smart technologies led by ICT and create economic enterprises and opportunities to leapfrog or at least compete with the more mature economies (Datta, 2015; Kitchin, 2014; Kant, 2013). However, on the other hand, there is an effort to refurbish or transform some of the existing cities (which include for example Ahmedabad, Bhubaneswar, Kochi, Pune, etc.) to smart cities with incorporation of new and digital technologies and provision of essential amenities and services and make them more efficient. Moreover, according to the Ministry of Urban Development of Government India, the key pillars of a smart city include a clean and pollution free environment, efficient urban mobility, ICT connectivity, and energy efficiency through which an entrepreneurial and investment friendly, environmentally and aesthetically attractive and socially participative atmosphere can be created (PTI, 2015). It is envisaged that a smart city model, particularly in India - while improving the essential services through supply of adequate clean water, upgrading sanitation and the solid waste management system, making available 24/7 power supply, and strengthening urban mobility - will make people more informed and competent and enable them for higher participation in decision-making and governance. Besides, it would reinforce economic performance, enhance energy efficiency and reduce environmental pollution (Pruseth \& Satapathy, 2015; PTI, 2015).

Nevertheless, there are criticisms against the smart city concept. It is argued that the concept is either too narrow or on the other side too open, 
expansive, and somewhat ambiguous (Greenfield, 2015; Russell, 2015). It may have been an outcome of the aggressive marketing by technological companies (such as IBM, CISCO, SIEMENS, etc.) to create new customers such as governments because of the reduction in their corporate customer base - and the willingness of city governments to show that they are trying to tackle the challenges and chaos of the rapidly growing cities (Datta, 2015; Townsend, 2013). Moreover, as Townsend (2013) suggested, a complex system like cities is intervened with peril, because truly smart cities would evolve and adapt technologies consistent with the way they grow naturally slowly, one at a time, sensitively and calmly (Townsend, 2013). There is also a need to re-think issues of poverty, urban informality and development, particularly in the Global South (McFarlane, 2011). Besides, there are the challenges of dealing with the issue of widening inequality and social polarization (Graham, 2002; Hollands, 2008). Similarly, it is argued that the new technology will break the almost primordial psychic relationship between people and the materials (Greenfield, 2015) and will lead to an inevitable tension within smart cities between serving global-, mobile capital and stationary ordinary citizens; between attracting and retaining an elite creative class and serving other classes; and between top-down, corporatized, centralized development and bottom-up, grassroots, decentralized and diffuse approaches (Kitchin, 2014).

However, despite the various criticisms arising from the work of Townsend (2013), Batty (2015) argued that the smart city is in many senses the contemporary city that changes from the bottom up and thus new and smart technologies are closely woven into this fabric, which is evolved based on smart growth principle (Calthorpe \& Fulton, 2000; Kunstler, 2003; Turner, 2007). Apart from technology, people and the governance system will remain central to the development. In case it is not so, it can only serve the elites instead of all city dwellers, and thus presents governance challenges to smart city development (Hollands, 2008). Consequently, it is argued that development of a smart city is not a challenge of technology or data, but rather a challenge of what role technology or data can play in providing a set of core public goods and infrastructures and protecting the people (Bhan, 2015).

\section{APPROACH OF THE INVESTIGATION}

A qualitative research method that includes review of literature and qualitative discussions with stakeholders was followed. Relevant published and unpublished literature and documents were reviewed to understand the theoretical paradigms behind smart cities, the governance system, and sociopolitical-, cultural-, and morphological aspects of cities in India. For this purpose, data bases like Scopus, ProQuest, Science Direct, Google Scholar and other relevant websites were searched. After initial screening, overall 78 articles that include peer reviewed research papers (39), books and book charters (23), study reports (9) and news articles and blogs (7) were selected. Selection of the articles was based on their source of publication, authenticity of publications and their relevance to the study. For example, peer reviewed journal articles and conference proceedings were given first priority, followed by official reports and reports from companies, newspaper reports, blogs from reputed scholars and opinions of people engaged in the smart city development process. The articles and reports were hierarchically coded according to the three stands of discourse, with peer reviewed journal 
articles and conference proceedings as the first priority, followed by reports, newspaper articles and blogs and opinions. Literature reviews and discourse analyses were conducted on three strands of discourse such as (1) theoretical perspectives of smart city (definitions, approaches, criticisms in general and smart city in an Indian context); (2) urban development processes; urban development challenges; city administration and challenges of smart city development in India; socio-political-, cultural-, and morphological aspects of cities; and (3) mapping the politico-cultural perspectives of smart city in India. The published research articles selected were critically reviewed to develop a theoretical background of smart cities and theoretical insights for plausible policy interventions. Similarly, published and unpublished reports and archival records relating to urban development processes, urban development challenges, city administration and challenges of smart city development in India were reviewed to comprehend the socio-political-, cultural-, and morphological aspects of cities in India. The opinions and blogs were used to supplement the discussions obtained from critical review of the articles and the developing storylines of the stakeholders.

In addition, discussions with relevant stakeholders were conducted by applying a random sampling process and using a semi-structured interviewing method. The stakeholders constitute academicians, experts in the field of urban development, urban development professionals, architects, engineers, urban development administrators, political scientist, political leaders and municipal councilors, students, business men, merchants and personnel from the industry. The selection of respondents was based on their awareness of- and engagement in the smart city development process after confirmation through an initial scrutiny. For this purpose, a search of profiles to identify prospective respondents was done by using online search engines such as Google; contacting relevant organizations and institutions; and examining various promotional materials and advertisements. An initial scrutiny of the searched profiles was done to observe the personal profiles and professional activities of prospective respondents and their engagements with regards to city development, and to avoid personal bias, prejudices and affiliation with the investigator. The selection of the respondents was confined to five of the twenty cities that have been selected in the first round for development as smart cities in India. The selected cities include Bhubaneswar, Pune, Vishakhapatnam, New Delhi and Ahmedabad, of which the locations are geographically well distributed so as to represent the country. Then, from the search and subsequent scrutiny, a list of 76 people (prospective respondents) was drawn by using a random sampling process. Once the list of prospective respondents was drawn, they were contacted via telephone, e-mail (if available) or personal contacts visiting them, to determine their suitability for the survey and to invite them to participate in the survey if found suitable. While selecting respondents, care was also taken not to discriminate against or exclude any person based on his/her race, gender, religion, social and economic status, occupation and similar attributes. Of the total contacts made, about 54 people (71.05\%) responded positively and gave their consent to participate of which 7 people later withdrew. Eventually, discussions were made with 47 willing participants. In addition, repeated discussions were made with some of the stakeholders which include experts, political scientists, professionals and academicians in an iterative manner to frame social solidarities and understand the level of participation and responsiveness in the governance of the cities. Table 1 presents the various demographic and professional attributes of the 
respondents. The gender, age and professions of respondents are also proportionately distributed, thus avoiding any bias.

The outcomes of the snowballing process of discussions over the period of June 2013 to December 2015 were compiled and qualitatively analyzed by using the narrative analysis method (Riessman, 1993).

Table 1. Profile of respondents

\begin{tabular}{llllll}
\hline Category (Profession) & Share & Gender & Share & Age & Share \\
\hline $\begin{array}{l}\text { Academicians } \\
\begin{array}{l}\text { Political leaders and } \\
\text { municipal councilors }\end{array}\end{array}$ & $8(10.6)$ & Male & $27(57.4)$ & $18-24$ & $6(12.8)$ \\
$\begin{array}{l}\text { Urban planning } \\
\text { professionals }\end{array}$ & $10(21.2)$ & Female & $20(43.6)$ & $25-35$ & $10(21.2)$ \\
$\begin{array}{l}\text { Architects } \\
\text { Engineers and }\end{array}$ & $8(17.1)$ & & $47(100.0)$ & $36-50$ & $14(29.8)$ \\
$\begin{array}{l}\text { Urban development } \\
\text { administrators }\end{array}$ & $6(12.8)$ & & $51-60$ & $12(25.6)$ \\
$\begin{array}{l}\text { Businessmen, and } \\
\text { merchants } \\
\text { industry personnel } \\
\text { Total }\end{array}$ & $10(21.2)$ & & $>60$ & $5(10.6)$ \\
\hline \multicolumn{2}{l}{ Note: The numbers in brackets show values in percentage. } & & \\
\end{tabular}

Note: The numbers in brackets show values in percentage.

\section{CHALLENGES OF DEVELOPMENT OF SMART CITIES IN INDIA}

\subsection{Challenges against the rationale behind the development of smart cities in India}

An enthusiasm is clearly visible among the political leaders, business leaders and professionals alike regarding the development of smart cities in India. Perhaps, the idea of building smart cities in India has emanated from the current poor plight of Indian cities and the visual experiences some of the European-, American- and of late Asian cities provide. An argument has emerged that if countries across the world could be able to build such cities, why should India fall behind ${ }^{3}$. However, the planning process is often found to be circumvented by formality and legality (Bhan, 2013; Roy, 2009) and the development of cities in India is observed to be more of a political decision than any other rationale ${ }^{4}$.Thus, professionals like urban planners do not have another choice than to comply with the political decisions ${ }^{5}$. However, experience has shown that many things have gone wrong in the past if the development has not been well conceived and not been well comprehended at the outset. For example, the case of ambitious programmes - like the Provision of Urban Infrastructure in Rural Areas (PURA) (Indra, 2012; Ramesh, 2012) and various urban development and renewal schemes which have met with failures or in some cases with mixed successes ${ }^{6}$, although decision makers, executive authorities and people advocating such programmes and schemes differ from this viewpoint. However, the results are clearly visible from the plight of the cities in India, which are facing

\footnotetext{
${ }^{3}$ Political leaders, urban development professionals and people from industries

${ }^{4}$ Expert opinion obtained from discussions with chief executives and councilors from municipalities of the selected cities, India

${ }^{5}$ Urban development professionals from Bhubaneswar and Pune

${ }^{6}$ Urban development professionals, urban planners, businessmen and expert opinion
} 
severe spatial, infrastructural and environmental challenges ${ }^{7}$. So, there is a need to explore how success in development of smart cities can be achieved, which essentially requires a discourse eliciting the challenges of building smart cities in India, and evolving a politico-cultural perspective that can be considered while planning to build such cities in India.

Important questions that emanate from this discourse include the following: What is a smart city and what does it entail? What is it intended for in India? Besides, while deciding to build smart cities, further questions arise as to whether new cities which should be smart should be built or whether some of the existing cities should be transformed to smart cities. In addition, debates arise on who these cities should be built for and what implications they will have on the country as a whole or on individual entities like people, society, economy, built environment, and so on. The answers to these questions would perhaps be able to provide directions that are essential for developing smart cities in India.

So, in the Indian context, there is a need to examine what is exactly aimed at while trying to build smart cities. Is it to transform the existing cities or part of cities to smart cities or is it to build absolute new cities improving all or some characteristics? In both cases, whether transforming the existing cities to smart cities or building new smart cities, the challenges to be faced are plenty. In the case of exiting cities, broadly the morphology of the cities, the huge population, the spatial extent, and the heterogeneity in urban functions are barriers in transforming the cities to smart cities. ${ }^{8}$ Rather, if one or two aspects are improved or made more functional - depending on the potential of the cities and the opportunities they offer - perhaps some success may be achieved. For example, cities which provide opportunities for entrepreneurial activities or educational or communicational activities (ICT industry development) - like Ahmadabad, Pune or Bhubaneswar could be transformed to entrepreneurial or pioneer cities. Cities like Pilani, Kharagpur, Roorkee, etc., which have a very strong presence in education and knowledge-based activities can be transformed to cities with smart people and so on.

The other aspect is whether the idea is to build new smart cities. Although, like Dholera, cities are being built -as global cities to compete with cities of mature economies (Datta, 2015), certain questions still arise such as: Is motivation behind building such cities at a huge expense well placed when the existing cities need more attention? Furthermore, who are these cities being built for - who will be benefited? What kind of cities will they be? Who will invest and what will their implication be on the society, and so on. For example, if digital connectivity (ICT connectivity) is taken as the sole or major consideration to make the cities smart and economically competitive, then digital cities should be built, which is far away from the concept of smart cities. Besides, there is no distinct requirement to make a few cities digitally connected, as digital connectivity is not necessarily bound by spatial boundaries. Rather, there is a necessity to digitally connect the whole country. Secondly, creating a few advanced (more recently known as green-, eco-friendly-, energy-efficient- and similar) buildings along with digital connectivity and using them for specific purposes in a specific area, cannot be counted as development of smart cities. Besides, developing new cities in proximity to existing large cities - like satellite cities with all the modern infrastructures - and using them for specific purposes, may not serve

\footnotetext{
${ }^{7}$ Urban development experts and political leaders

${ }^{8}$ View of urban planning professionals and experts
} 
the purpose. The reasons being that with the fast expansion of cities, which has been witnessed over last decades, these new developed areas will soon be engulfed by the existing cities and be assimilated with them. Furthermore, the unequal infrastructure development may create disparity among different areas of the existing cities ${ }^{9}$. Thus, building new cities or transforming a part of the city with digital connectivity and advanced buildings does not make a city smart. On the contrary, it may create spatial, infrastructural and environmental inequality, and add unwarranted pressure on the existing built environment, which may compromise the sustainability of both the new and existing cities. Besides, it requires investment, of which a lion's share is likely to come from the public exchequer and from common tax payers, whereas only limited people or entities such as enterprises and the corporate sector will be benefited at the expense of the common people ${ }^{10}$.

\subsection{Challenges of the prevalent general characteristics of Indian cities}

There is a need to examine the general prevalent characteristics of Indian cities and understand if they could suffice to the mentioned characteristics on which development of a smart city rests. Most of the Indian cities regardless of their size and character - have some economic functions. However, barring a very few cities, most of the cities lack innovation, entrepreneurship, trademarks, productivity and flexibility of the labor market as well as integration in the national and international market ${ }^{11}$. Although, many medium and large cities of late boast of a higher education system and the level of qualification or education of the people has been enhanced, they lack quality and employability (Aspiring Minds, 2010; Sarkar \& Choudhury, 2014). There is some social interaction and integration but it is quite sporadic and sectoral, which is evident from intolerance and unwarranted communal happenings in the city life over the years. The participation of people in public life and the receptive attitude and openness towards the outer world is very limited ${ }^{12}$. These features of the cities indicate towards a lower level of smartness of the urban population in the country. The $73^{\text {rd }}$ and $74^{\text {th }}$ amendment of the Indian constitution enabled governance by people at local level. It entails facets of political participation, services for citizens and the functioning of the administration. However, it is observed that the local governance has been limited to political processes by political leaders and executives and the will and wishes of the majority of the citizens are grossly being neglected. The local governance has become a tool for personal benefits of unscrupulous politicians, greedy businessmen and entrepreneurs $^{13}$. For example, the cityscape and development of industrial and commercial zones are dictated by real estate developers and industrial entrepreneurs. Thus, the opportunity for smart governance is minimal. In recent times there has been enhanced local and international accessibility in the form of sustainable physical transportation systems and information and communication technologies. Arguments have emerged that ICT offers distinct advantages to the cities, which may provide opportunities for smart

\footnotetext{
${ }^{9}$ View of urban planning professionals and experts and personnel from industries

${ }^{10}$ Expert opinion: Professionals and academicians involved in urban development

${ }^{11}$ Expert opinion: Professionals involved in urban development and members from Chamber of Commerce, India

${ }^{12}$ Political scientist and experts in local governance

${ }^{13}$ Academicians and experts in urban and regional development, political scientist and expert in local governance
} 
information transfer and aid in mobility. However, despite being digitally accomplished, the level of physical movement in cities is still enormous. The traffic scenario is deplorable (Alam \& Ahmed, 2013; Kumar, 2013; Rao \& Rao, 2012). Public transportation is not a popular choice nor efficient enough to encourage people to adopt it (Alam \& Ahmed, 2013). The greed of the automobile industries, the business model around automobile and related service industry, such as the finance sector, insurance sector, energy sector, etc., and the false vanity of owning a private car make the situation worse $^{14}$. On the other hand, although it is emphasized that the ICT sector in cities has developed by leaps and bounds, the service providers are more interested in business and profits than in efficient services. Consequently, lower performance is experienced ${ }^{15}$. With regard to environment, the question is whether the cities have attractive natural conditions such as climate, green open space, level of pollution, resource management and efforts towards environmental protection. It is observed that open drainage and poor sewerage systems are common. Solid waste management is almost non-existent in many cities in India and pollution levels are undesirably high (Annepu, 2012; Bundela et al., 2010). Furthermore, paradoxes are found in socio-cultural aspects such as culture, health, safety, housing, tourism, etc. The country has a great culture but often lacks communal and social harmony ${ }^{16}$. Health care service has become an unsavory business model with the collusion of heath care centers, pharmaceutical industries, diagnostic centers, medical insurances and other stakeholders. Maximization of profit is the major motive, often at the expense of services (Das \& Sonar, 2012). The poor environment and unwarranted physical and mental stresses are leading to more people in the cities being unhealthy. Safety and security in the cities are on the wane. Terrorism and crime have become part of the city life. The housing scenario is no better. Slums, squatters and urban sprawl are an integral part of the cities ${ }^{17}$. Many of the cities have good tourism potential, which is the only silver lining (Gyan Research and Analytics Pvt. Ltd., 2012; KPMG, 2013) .

In the wake of such challenges, it is observed that most of the cities in India are not tuned towards transforming to smart cities. Because of the challenges of people, governance, living- and environmental factors, it is also difficult to comprehend if new smart cities can be developed.

\subsection{The challenges of stakeholders' participation in development of cities in India}

A coalition of relevant stakeholders is imperative and their collaborative and participative approach is vital to sustainable development of cities. However, most studies undertaken to assess the functioning of municipalities or urban local bodies in India point out that their performance has deteriorated over time (Aijaz, 2007; Fahim, 2009). They are confronted with a number of challenges, such as inefficiency in the conduct of business, ineffective participation by the weaker sections of the population in local governance, weak financial condition, lack of transparency in the planning and implementation of projects, etc., which affect their performance adversely (Aijaz, 2007; Fahim, 2009). Under this premise the $74^{\text {th }}$

\footnotetext{
${ }^{14}$ Expert opinion and professionals from urban development field

${ }^{15}$ Member from CCI and professionals from urban development field

${ }^{16}$ Expert opinion: Political scientists

${ }^{17}$ Expert opinion from local governance and political scientist
} 
Amendment Act, 1992 of the Indian Constitution was enacted with the following aims: to provide a basis for the State Legislatures to guide the State Governments in the assignment of various responsibilities to municipalities/ urban local bodies and to strengthen their governance in a bid to achieve democratic decentralization and provide constitutional endorsement to local self-governance authorities with participation of people at the grassroots level, aided with devolution of greater functional responsibilities and financial powers to municipalities/ urban local bodies; adequate representation of weaker sections and women in municipalities; regular and fair conduct of municipal elections; and constitution of Wards Committees, District Planning Committees, Metropolitan Planning Committees and State Finance Commissions. The central objective of this amendment act is the decentralization of planning and decision making procedures at urban area level. It also has the implicit intention of removing centralized notions of control and monopoly over development of resources. In this respect, the local governments or councils are representative of the people and they have the right of governance of their cities and are empowered to take appropriate decisions on behalf of the people. Furthermore, people or stakeholders are also consulted at the planning stage of any city development/ redevelopment process and feedbacks are taken before finalizing the plan. Based on this supposition, the system seems to work fine. However, it is observed that while many provisions of the $74^{\text {th }}$ amendment act are met at structural level, such as constitution of three types of Urban Local Bodies, reservation of seats in the municipal councils, and constitution of State Financial Commissions, yet same cannot be said about certain provisions such as the constitution of Wards Committees, District Planning Committees and Metropolitan Planning Committees because of the lack of commitment from the State Governments, which essentially hinders the stakeholders' participation (Aijaz, 2007; Fahim, 2009; Govinda Rao \& Singh, December 8-10, 1999; Singh \& Rao, 2006). Besides, although the municipal councils or local governments are set up constitutionally, most of the decisions are taken based on the pull and push factors (Das \& Sonar, 2013; Stone, Clarence Nathan \& Sanders, 1987). In some instances, the individuals representing the council sway the decisions although they may have conflict of interest and in Indian conditions conflict of interest is not strictly defined. Political hegemony takes precedence over scientific logic and rationality. The council is also at times not well advised of their decisions by the professionals - maybe due to various personal and professional reasons such as individual affiliation to the decision makers, fears of loss of job, personal benefits, lack of knowledge or skills, rejection of professional advice, or the likes ${ }^{18}$. Above all, the stakeholders or the people at large are essentially not a part of such decision making. Also, although the system of feedback from the people or stakeholders does exist and is sometimes practised, it is done at a very late stage where their wishes or arguments do not hold much significance and as such are not given enough priority ${ }^{19}$. Besides, in some cases there are peoples' committees at various levels - from neighborhood-, suburban- to city level, and also at various professional levels like chamber of commerce, industry, culture, etc., - whose advice is sought. However, these committees do not have much authority and are basically advisory in nature without much significance in

\footnotetext{
${ }^{18}$ Expert opinion: Political scientists and local governance expert

${ }^{19}$ Executive officers, urban development authorities
} 
the decision making process ${ }^{20}$. Moreover, these committees are also characterized by conflicts, fractions and self-motives, thereby not contributing much to the democratic decision making process of the development of the cities as envisaged by the constitution ${ }^{21}$ (Stone, Clarence Nathan \& Sanders, 1987).

This condition is mainly attributed to a lack of responsibility and accountability and lack of respect to the stakeholders. Although, the said constitutional amendment act was enacted in a spirit of governance at the grassroots level and it can be viewed as being successfully functional from a structural point of view, the role of various stakeholders such as common citizens of the city/ urban area, businessmen, civil society, etc., are largely ignored, thereby confining the city development process to the hands of a few technical and administrative people under the auspices of local political elected leaders ${ }^{22}$. Thus, the question arises: when there is a clear mandate from the constitution, which strengthens the local governance with a spirit for sustainable development of cities - per se urban areas - by preparing and implementing plans for economic development and social justice, why are most of the cities of India languishing with improper development and poor services and facilities? The argument here is that possibly the top down approach of governance - even within the urban local governance; the ignorance and non-assimilation of a critical mass of stakeholders; and the manipulation of pressure groups such as real estate and property developers with a sole aim of short term gain, are the major barriers in achieving sustainable development ${ }^{23}$. Reflecting these concerns, it is argued here that in the city development process, procedural equity is of great importance to achieve desired smart growth and appropriate sustainable development ${ }^{24}$. It involves much more than legalistic and bureaucratic procedures for establishing and enforcing obligations and rights. In addition, it needs to embrace wider processes of public engagement, where multiple democratic and participative forms and channels are brought into play to foster participation and engagement with processes of change. This concern suggests that people should have access into public decision-making processes at different points (in particular at the junction of public and private decision-making affecting common city people). This requires a balancing of democratic and participative methods of engagement with decision-making, rather than a displacement of necessary democratic responsibilities by urban local bodies.

It is thus construed that there are several challenges which bar the development of smart cities in India. The challenges range from the rationale behind the decision to build smart cities, prevalent spatial and social characteristics, to issues in urban governance and stakeholders' participation. However, even if the first two challenges (rationale and prevalent city characteristics) are left out, the major issue in the current scenario is the minimal participation of various social solidarities in the development of Indian cities. Therefore, while developing smart cities in the country, the local urban governance issue needs to be resolved. This essentially seeks a new politico-cultural perspective that can bring fruitful engagement among the stakeholders and lead to development of smart cities based on the

\footnotetext{
${ }^{20}$ Members of Chamber of commerce

${ }^{21}$ Expert opinion: Political scientists and local governance expert

${ }^{22}$ Expert opinion: Political scientists and local governance expert

${ }^{23}$ Urban development professionals including architects and engineers

${ }^{24}$ Expert opinion: Local governance and urban development
} 
requirements of the various solidarities of the society rather than benefiting only one segment of the society.

\section{POLITICO-CULTURAL PERSPECTIVES FOR DEVELOPMENT OF SMART CITIES}

As evident from the previous sections, it is ironic that in a populous, diverse and democratic country like India, most of the urban planning and development are concentrated in the hands of a few authorized people (executives and decision makers) who more often succumb to demands of the political/local leaders and/or pressure groups. Although, the $74^{\text {th }}$ amendment of the constitution - in an attempt to involve local leaders and people in the development of their cities - has leveraged the urban local bodies to take decisions, it is not necessarily true that the local political leaders, who are divided in ideology, race, religion, caste and so on, represent the requirements of common people ${ }^{25}$. In other words, the opinions or the decisions of the political leaders or pressure groups at times hardly reflect the demands of the society. Despite the constitutional interventions, the planning process largely remains a top down approach. Therefore, at the current state, it would be wrong to assume that development of smart cities in India will follow a different approach ${ }^{26}$.

However, sustainability of smart cities can be achieved if a smart growth principle for development is adopted. Examples across the world are plenty. The cities of Europe, particularly from Austria, Switzerland, Benelux and Scandinavian countries, are the leading flag bearers which have shown how cities should be developed through application of smart growth principles and effective governance. Another glaring example is the participative city governance (with effective participation from all strata of the society) of Vancouver in Canada. The smart growth principles advocate that growth of a city is accomplished by combining the various discourses of physical and spatial issues into a rational sustainable development that integrates economic, environmental and social equity issues. It also invokes the notions of urbanity, creating a sense of a coherent community (Calthorpe \& Fulton, 2000; Kunstler, 2003; Turner, 2007). It is a strategy that targets the physical development of urban regions, having strong social, economic and political components with public participation. It is an inclusive multi-actor planning process (Brunet-Jailly, 2008; Scott, 2007). However, it is evident from many cases in India that multi-actor planning and stakeholders' involvement in planning of the development is a hugely cumbersome and difficult process. The conventional approaches of stakeholders' participation may not assure successful planning and development. It needs a new paradigm to make the participatory planning more inclusive and effective. The challenge, however, particluarly while developing smart cities, can be overcome by creating a platform by applying theories of social organization and governance, such as the cultural theory or refurbishing the theory of Dahl's pluralist democracy (Douglas \& Wildavsky, 1983; Schwarz \& Thompson, 1990; Thompson, Ellis, \& Wildavsky, 1990; Thompson, Rayner, \& Ney, 1998; Thompson, 2008; Verweij \& Thompson, 2006) .

The cultural theory maps a fourfold typology of social solidarity: the individualist, hierarchist, fatalist and egalitarian (Douglas \& Wildavsky,

\footnotetext{
${ }^{25}$ Expert opinion: local governance

${ }^{26}$ Academicians and political scientists
} 
1983; Thompson, Rayner, \& Ney, 1998). For the individualist, man is inherently self-seeking and atomistic. The nature is benign and forgiving, and can be able to recover from any exploitation. Trial and error in selforganizing, ego-focused networks (markets) is the way to go. Individualist actors trust others until they give them reason not to and then retaliate in kind (Rapoport, 1985). They institute equality of opportunity (symmetrical transactions) and promote competition, which is no accountability. They see it as only fair that those who put most in get most out. The world, in the hierarchist solidarity, is controllable. Man is malleable, deeply flawed but redeemable by firm, long-lasting and trustworthy institutions. Fair distribution is by rank and station or, in the modern context, by need, with the level of need being determined by an expert and dispassionate. Hierarchies set all sorts of limits on competition. Fatalist actors (the common men here) find neither rhyme nor reason in nature and know that man is fickle and untrustworthy. Fairness, in consequence, is not to be found in this life and there is no possibility of effecting change for the better. The egalitarian solidarity is almost the exact opposite. The nature - and society in this case - are fragile and intricately interconnected and man is essentially caring and sharing, until corrupted by the coercive and non-egalitarian institutions of markets and hierarchies. It is not enough that people start off equal, but they must end up equal. Trust and leveling go hand in hand, while institutions that distribute unequally are distrusted. Voluntary simplicity is the only solution to the societal problems. These solidarities suggest that each generates its own storyline which contradicts those that are generated by other solidarities (Douglas \& Wildavsky, 1983; Thompson, Rayner, \& Ney, 1998) and that the complex dynamics of their interactions can lead to sometimes destructive and sometimes constructive directions (Beck et al., 2011). Each of the solidarities distils certain elements of experience and wisdom that are missed by the others, and as such each provides a clear expression of the way in which a significant portion of the populace feels they should live with one another and with the society. It is important that some sort of account be taken of all of them in the policy process and that each of the three active voices - individualism, egalitarianism and hierarchism - and the passive voice (fatalist) be heard and become responsive to the other in the state of affairs (Verweij \& Thompson, 2006). This approach has been put into practice and has observed success. Case studies include the resolving of the water sanitation system in Kathmandu valley; the Chattahoochee issue in Atlanta; access to service delivery (particularly in sanitation and solid waste management) by people in Kamapala; and ameliorating the problem of hygiene and sanitation in Yaoundé (Beck et al., 2011; Parrot, Sotamenou, \& Dia, 2009; Tukahirwa, Mol, \& Oosterveer, 2010). Although, in all these cases the engagement of different solidarities brought some clumsy solutions, it provided some prospect of collectively accepted progress. For example, in the case of Kathmandu valley, this cultural theory inspired mechanism has led to the scenario that no conservationist group (egalitarian) can argue for 'no growth' in the face of the highly emotive condition of insufficient water for drinking. Similarly, the situation is recognized as beyond any promises the water agencies (hierarchist) might care to make in order to maintain control over their framing of the problem for their way of problem solving. Although, the private sector of water-tanker supply (individualist) struggles to sell its services, it found a few crumbs of comfort (Beck et al., 2011).

Based on this premise, the whole Indian society can be placed in these four solidarities as shown in Figure 1. Adopting the premise of the works of Beck et al. (2011) and (Kubanza, Das, \& Simatele, 2017), the four 
solidarities were developed and stakeholders were grouped under each of the solidarities after repeated discussions with some of the stakeholders and surveyed experts. Accordingly, as seen in Figure 1, the common and individual people like professionals, academicians, merchants, students, laborers, etc., are the fatalists; the industry, corporate sector, entrepreneurs and market represent the individualists; the governance system, political parties, political leaders, bureaucracy, etc., represent the hierarchists; and the Non-Governmental Organizations (NGOs), community based organizations (CBOs) and the society as a whole are the egalitarian actors. In the case of urban development in India, it is evident that the fatalists are the sufferers and that they are not heard ${ }^{27}$. It is only the hierarchists (the political authorities and bureaucracy), and the individualists (the market forces/ industry) who dominate the process. The market forces decide the functioning of the system in an unwarranted way and there are significant gaps in the functioning of the hierarchy (the governance system) which should be overseeing and articulating the system for the proper function and results to a non-egalitarian society ${ }^{28}$. The egalitarian voices represented by CBOs, and NGOs are handicapped by shortage of resources and patronage and are donor dependent, therefore they are not always effective and are often not heard ${ }^{29}$.

\section{Fatalism}

Common people and individual people like professionals, academicians, merchants, students, laborers, etc.: Voices are not heard, apathy and unwillingness to participate in any development process. Lack of trust and confidence in the government, new policy programs, institutional landscape and individual benefit.

\section{Individualism}

Industries, private companies, entrepreneurs, corporate sector: Don't care about common urban dwellers and higher profit motive.

Figure 1. Perceptions of social solidarities in Indian cities (Adopting the premise of works of Beck et al. (2011) and Kubanza, Das, and Simatele (2017) and discussions with stakeholders)

However, the democratic process insight suggests that any planning and/ or policy process needs to ensure that all the actors be involved and their storylines be fully developed into scenarios that are then engaged with one another - it may be noisily and argumentatively - and then to bring out a solution.

\footnotetext{
${ }^{27}$ Political scientists, professionals, government officials, people form NGOs and CBOs and academicians

${ }^{28}$ Academicians, students and political scientists

${ }^{29}$ Political scientist, local governance expert, urban development professionals
} 
Based on the classic theory of refurbished pluralist democracy (Dahl, 1989) and adopting the works of Beck et al. (2011) and Kubanza, Das, and Simatele (2017) and stakeholders' opinion (through repeated discussions with various stakeholders and experts to arrive at the most acceptable phenomena that are occurring or are expected to occur in the governance system) a mapping between participation of stakeholders and responsiveness of the governance system was done and presented in Figure 2. As seen from Figure 2, by putting participation and responsiveness - the two pillars of a democratic process - in a nine provinces (blocks) map, it is apparent that as participation and responsiveness increase, deliberative quality also increases. In the current scenario, although there is no closed hegemony in the Indian urban local governance (as shown in block 1) where one voice drowns all and fatalists are not heard because of the democratic governance system, it rests in scenarios with participation and responsiveness varying between low to medium as shown by squares 2, 4, 5. Essentially, such scenarios are not ideal because of either lack of adequate and effective participation and/or adequate responsiveness. It is also inappropriate to expect an ideal scenario (as represented by block 9), where each voice is heard and responded to. However, there is a possibility of increased participation and responsiveness if all four solidarities are participating and responding (as represented by Block 6 and 8), which may lead to the ideal scenario further on as the process gains maturity ${ }^{30}$. Perhaps, the interaction of the four solidarities is not to result in an elegant solution as many expect and although the engagement and socio-economic trade-off among them could provide a clumsy solution, it could be responsive to each other and acceptable to all (Beck et al., 2011; Kubanza, Das, \& Simatele, 2017; Thompson, 2008; Verweij \& Thompson, 2006). Therefore, while developing smart cities, it is highly imperative that all these solidarities - which represent common men (citizens including teachers, students, doctors, professors, merchants, laborers, rickshaw pullers and so on); the industry (entrepreneurs, the corporate sector); the governance (government, bureaucracy, professionals, political leaders); CBOs and NGOs and so on from across the whole society - must engage in a constructive, but maybe clumsy manner. They must be part of the development process and develop a kind of belonging so that the development and sustainability of smart cities in India could become a reality. Or else, if the development process is left in the hands of only the hierarchist and individualist actors, they could only produce short term solutions or may simply use it for their myopic benefits. Consequently, the development of smart cities in India will suffer and may perhaps not be realized the way it is envisaged ${ }^{31}$. The advantages of this paradigm lie in clustering the plethora of stakeholders into four social solidarities, which would reduce the plethora of stakeholders to manageable groups that would facilitate effective constructive engagement among them based on their storylines (demands) and arrive at compromises through concessions rather than consensus. In other words, every solidarity will get maximum of what they want and minimum of what they don't want (Thompson, 2008).

\footnotetext{
${ }^{30}$ Political scientists, urban development professionals, government officials, people from community organisations and common people

${ }^{31}$ Urban development professionals, members from business and industry, students and political scientists
} 


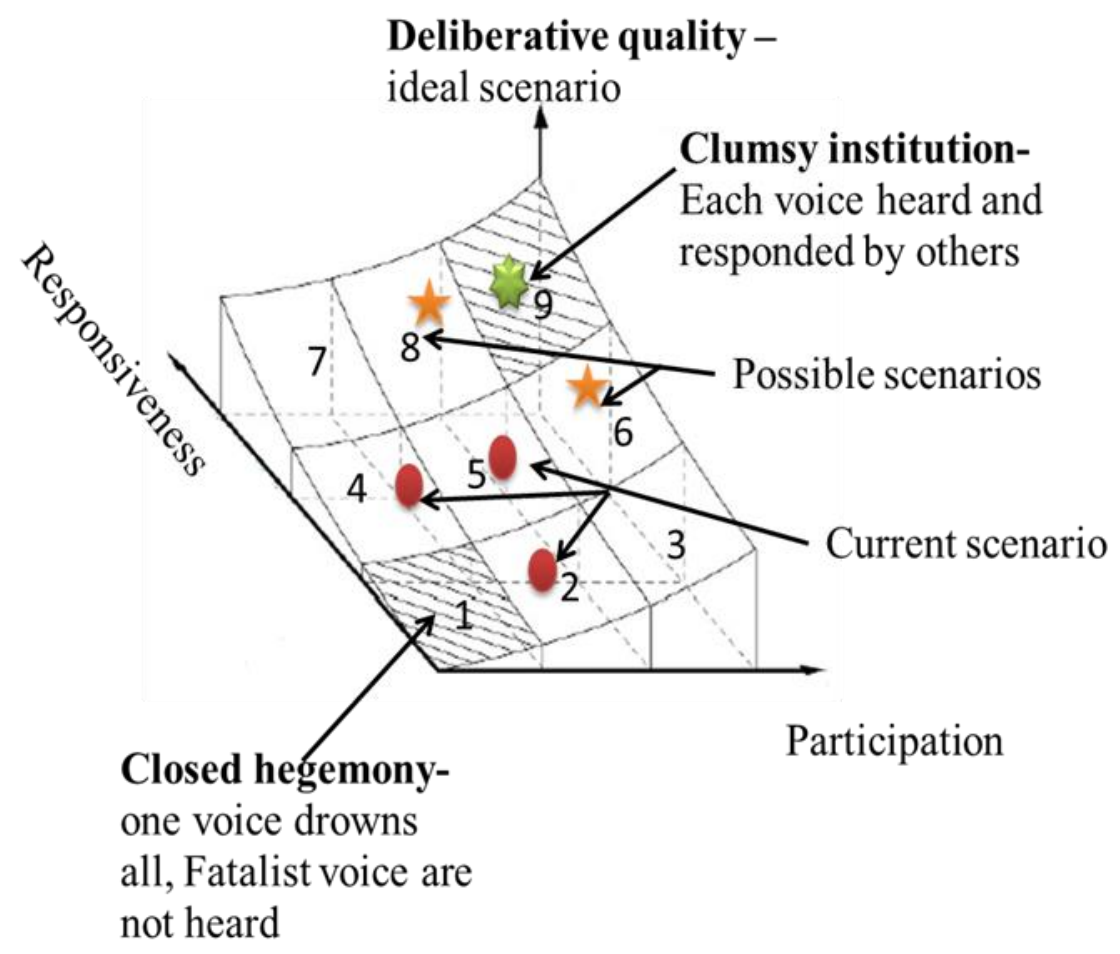

Figure 2. Adoption of the theory of plural democracy for urban governance (addition of politico-cultural dimensions) to aid development of smart cities in India (Adoption from Beck et al. (2011); Dahl (1989) and Kubanza, Das, and Simatele (2017) and stakeholder's

perception).

\section{CONCLUSIONS}

This article was focused on examining the challenges of smart city development in India; and mapping a politico-cultural discourse for engagement and participation of different social solidities to realize the goals of smart city development in India. The first challenge is to clearly understand what is meant by the smart city concept and how it is relevant in the Indian context. Secondly, whether the challenges provided by the general and morphological characteristics of existing cities are attuned to transform them to smart cities. Besides, the article explored how the challenges and inadequacies of the current governance system may become a barrier in the development of smart cities in the country and how it can be overcome by a cultural theory premised planning process.

There are no equivocal definitions of a smart city and different approaches for developing smart cities are seen. In the Indian context, as argued by scholars, government authorities and practitioners, although there is a lack of clarity, two distinct approaches are experienced such as building cities like Dholera from scratch with an integration of ICT with urban planning to further economic goals and build competing cities at global level. On the other hand, there is the refurbishing of existing cities such as Ahmedabad, Bhubaneswar, Kochi, Pune, etc. with an integration of ICT and strengthening of the essential urban infrastructure. Apparently, India will have context specific smart cities of its own genre and thus needs a different planning perspective to build these cities. Therefore, this article argued for 
a new politico-cultural perspective in the governance system for development of smart cities, based on the cultural theory. It advocated for constructive engagement among the various solidarities of the society, which represent the various stakeholders, such as common people (fatalists), industry and market forces (individualists), governance system (hierarchists) and community-based and non-governmental organizations (egalitarian). This politico-cultural perspective is envisaged to provide a platform for the fruitful engagement among the various stakeholders, listening to each other's storylines and arriving at compromises through concessions, although it may be in a very clumsy way as against the current approach of democratic consensus and without significant participation of the society and stakeholders. It could be able to develop a sense of belonging and make them part of the development process, which is highly essential for development of smart cities and their long term sustainability in India. Moreover, it has the advantage of grouping the often experienced insurmountable and unmanageable numbers and categories of stakeholders into manageable four solidarities and listening to their demands and developing their storylines more effectively that could enable acceptable and inclusive development of smart cities in India.

\section{REFERENCES}

Aijaz, R. (2007). "Challenges for Urban Local Governments in India". Working Paper 19 Asia Research Centre (ARC) London School of Economics \& Political Science. Retrieved from www.lse.ac.uk/collections/asiaResearchCentre on February 13 2014,

Alam, M., \& Ahmed, F. (2013). "Urban Transport Systems and Congestion: A Case Study of Indian Cities". Transport and Communications Bulletin for Asia and the Pacific, 82, 3343.

Annepu, R. K. (2012). "Sustainable Solid Waste Management in India". (Master), Columbia University, New York.

Aspiring Minds. (2010). "National Employability Study It/Ites Sector: Key Findings and Intervention Indicators". Aspiring Minds Assessment Pvt. Ltd.

Batty, M. (2015). "Smart Cities by Anthony Townsend: A Review". Retrieved from http://www.spatialcomplexity.info/archives/2419

Batty, M., Axhausen, K. W., Giannotti, F., Pozdnoukhov, A., Bazzani, A., Wachowicz, M., ... Portugali, Y. (2012). "Smart Cities of the Future". The European Physical Journal Special Topics, 214(1), 481-518.

Beck, M. B., Thompson, M., Ney, S., Gyawali, D., \& Jeffrey, P. (2011). "On Governance for Re-Engineering City Infrastructure". Proceedings of the Institution of Civil EngineersEngineering Sustainability, 164(2), 129-142.

Bhan, G. (2013). "Planned Illegalities: Housing and the 'Failure' of Planning in Delhi: 19472010". Economic and Political Weekly, 48(24), 58-70.

Bhan, G. (2015). "Asking the Wrong Question: Smart Cities in Contemporary Urban India1". In Stollmann, J., Wolf, K., Brück, A., Frank, S., Million, A., Misselwitz, P., . . S Schröder, C. (Eds.), Beware of Smart People! Redefining the Smart City Paradigm Towards Inclusive Urbanism (pp. 100-112). Berlin.

Brunet-Jailly, E. (2008). "Vancouver: The Sustainable City". Journal of Urban Affairs, 30(4), 375-388.

Bundela, P. S., Gautam, S. P., Pandey, A. K., Awasthi, M. K., \& Sarsaiya, S. (2010). "Municipal Solid Waste Management in Indian Cities-a Review". International Journal of Environmental Sciences, 1(4), 591-606.

Calthorpe, P., \& Fulton, W. (2000). The Regional City: Planning for the End of Sprawl. Washington, DC: Island Press.

Cavada, M., Hunt, D., \& Rogers, C. (2014). "Smart Cities: Contradicting Definitions and Unclear Measures". Proceedings of World Sustainability Forum 2014. Retrieved from http://www.sciforum.net/conference/wsf-4.

Cohen, B. (2013). "The 10 Smartest Cities in North America". Retrieved from http://www.fastcoexist.com/3021592/the-10-smartest-cities-in-north-america 
Dahl, R. A. (1989). Democracy and Its Critics. New Haven, Connecticut: Yale University Press.

Das, D., \& Emuze, F. (2014). "Smart City Perspectives of Bloemfontein, South Africa". Journal of Construction Project Management and Innovation, 4(2), 930-950.

Das, D., \& Sonar, S. G. (2012). "Urban Health Care Dynamics in India - an Unsavoury Business Model". Review of Business \& Technology Research (RBTR), 8(1), 162-169.

Das, D., \& Sonar, S. G. (2013). "Development of Smart Cities in India - an Illusory Concept". Proceedings of 61st National Town and Country Planning Congress, Ahmedabad, India, pp. 425-430.

Datta, A. (2015). "New Urban Utopias of Postcolonial India: 'Entrepreneurial Urbanization'in Dholera Smart City, Gujarat". Dialogues in Human Geography, 5(1), 3-22.

De Jong, M., Joss, S., Schraven, D., Zhan, C., \& Weijnen, M. (2015). "Sustainable-SmartResilient-Low Carbon-Eco-Knowledge Cities; Making Sense of a Multitude of Concepts Promoting Sustainable Urbanization". Journal of Cleaner Production, 109, 25-38. doi: https://dx.doi.org/10.1016/j.jclepro.2015.02.004.

Deakin, M. (2014). "Smart Cities: The State-of-the-Art and Governance Challenge". Triple Helix, 1(1), 1-16. $\quad$ Retrieved from https://triplehelixjournal.springeropen.com/articles/10.1186/s40604-014-0007-9.

Douglas, M., \& Wildavsky, A. (1983). Risk and Culture: An Essay on the Selection of Technological and Environmental Dangers. Berkeley: University of California Press.

Fahim, M. (2009). "Local Government in India Still Carries Characteristics of Its Colonial Heritage". City mayor, Government. Retrieved from http://www.citymayors.com/government/india government.html on February 12, 2013,

Florida, R. (2005). Cities and the Creative Class. London: Routledge.

García, B. (2004). "Cultural Policy and Urban Regeneration in Western European Cities: Lessons from Experience, Prospects for the Future". Local economy, 19(4), 312-326.

Giffinger, R., Fertner, C., Kramar, H., Kalasek, R., Pichler-Milanovic, N., \& Meijers, E. (2007). "Smart Cities. Ranking of European Medium-Sized Cities". Vienna UT: Centre of Regional Science.

Govinda Rao, M., \& Singh, N. (December 8-10, 1999). "How to Think About Local Government Reform in India: Incentives and Institutions". Proceedings of Second Generation Indian Economic Reforms, Chennai.

Graham, S. (2002). "Bridging Urban Digital Divides? Urban Polarisation and Information and Communications Technologies (Icts)". Urban Studies, 39(1), 33-56.

Greenfield, A. (2006). Everyware: The Dawning Age of Ubiquitous Computing. Boston: New Riders.

Greenfield, A. (2015). "Practices of the Minimum Viable Utopia". In Stollmann, J., Wolf, K., Brück, A., Frank, S., Million, A., Misselwitz, P., . . S Schröder, C. (Eds.), Beware of Smart People! Redefining the Ssmart City Paradign Towards Inclusive Smart Urbanism (pp. 916). Berlin.

Gyan Research and Analytics Pvt. Ltd. (2012). "Tourism Potential in India". Retrieved from http://gyananalytics.com/Tourism\%20Potential\%20in\%20India.pdf.

Hancke, G. P., de Carvalho e Silva, B., \& Hancke Jr., G. P. (2013). "The Role of Advanced Sensing in Smart Cities". Sensors, 13(1), 393-425.

Hollands, R. G. (2008). "Will the Real Smart City Please Stand Up? Intelligent, Progressive or Entrepreneurial?". City, 12(3), 303-320.

Indra, R. K. (2012). "Information \& Analysis, Providing Urban Amenities to Rural Areas (Pura)". Retrieved from https://sites.google.com/site/errajanikantissuediscussion/policyprogram-of-govt-of-india/pura

Kant, A. (2013). "In India, Leaders Are Building Smarter Cities from the Ground Up". Retrieved from http://asmarterplanet.com/blog/2013/09/in-india-leaders-are-buildingsmartercities-from-the-ground-up.html

Kitchin, R. (2014). "The Real-Time City? Big Data and Smart Urbanism". GeoJournal, 79(1), $1-14$.

Komninos, N. (2002). Intelligent Cities: Innovation, Knowledge Systems, and Digital Spaces. London: Taylor \& Francis.

Kourtit, K., Nijkamp, P., \& Arribas, D. (2012). "Smart Cities in Perspective-a Comparative European Study by Means of Self-Organizing Maps". Innovation: the European Journal of Social Science Research, 25(2), 229-246.

KPMG. (2013). "Travel and Tourism Sector: Potential, Opportunities and Enabling Framework for Sustainable Growth". Retrieved from http://docplayer.net/13428224Travel-and-tourism-sector-potential-opportunities-and-enabling-framework-forsustainable-growth.html. 
Kubanza, N. S., Das, D. K., \& Simatele, D. (2017). "Some Happy, Others Sad: Exploring Environmental Justice in Solid Waste Management in Kinshasa, the Democratic Republic of Congo". Local Environment, 22(5), 595-620. doi: http://dx.doi.org/10.1080/13549839.2016.1242120.

Kumar, K. N. (2013). "Daunting Traffic Scenario: Delhi Comes to a Standstill in Coming Years". The Economic Times. Retrieved from http://economictimes.indiatimes.com/news/economy/infrastructure/daunting-trafficscenario-delhi-to-come-to-a-standstill-in-seven-years/articleshow/19009498.cms

Kunstler, J. H. (2003). The City in Mind: Notes on the Urban Condition. New York: Simon and Schuster.

Lombardi, P. (2011). "New Challenges in the Evaluation of Smart Cities". Network Industries Quarterly, 13(3), 8-10.

Martin, J. (1978). The Wired Society. Upper Saddle River, NJ: Prentice-Hall, Inc.

McFarlane, C. (2011). Learning the City: Knowledge and Translocal Assemblage: WileyBlackwell.

Mercer Study. (2014). "2014 Quality of Living Worldwide City Rankings - Mercer Survey". Retrieved from https://www.mercer.com/newsroom/2014-quality-of-living-survey.html

Moir, E., Moonen, T., \& Clark, G. (2014). "What Are Future Cities? Origins, Meanings and Uses". Government office for Sciences, UK. Retrieved from https://www.gov.uk/government/uploads/system/uploads/attachment_data/file/337549/14820-what-are-future-cities.pdf.

Mollenkopf, J. H. (1983). The Contested City. Princeton: Princeton University Press.

Nijkamp, P., \& Kourtik, K. (2011). "Joint Programming Initiative (Jpi) on Urban Europe. Global Challenges and Local Responses in the Urban Century. A Scoping Document ". VU University Amsterdam.

Parrot, L., Sotamenou, J., \& Dia, B. K. (2009). "Municipal Solid Waste Management in Africa: Strategies and Livelihoods in Yaoundé, Cameroon". Waste management, 29(2), 986-995.

Peterson, P. E. (1981). City Limits: University of Chicago Press.

Picon, A. (2015). Smart Cities: A Spatialised Intelligence: John Wiley \& Sons.

Pruseth, S. K., \& Satapathy, S. (2015). "Making Smart Cities 'Inclusive' in India". Retrieved from http://www.rediff.com/money/special/special-making-smart-cities-inclusive-inindia/20150910.htm

PTI. (2015). "100 Smart Cities to Go Green, Be Environment Friendly". Retrieved from http://www.rediff.com/money/report/smart-cities-to-go-green-be-environmentfriendly/20150928.htm

Ramesh, J. (2012). "A P J Kalam's Pura Project a 'Complete Failure' ". Retrieved from http://economictimes.indiatimes.com/news/politics-and-nation/a-p-j-kalams-pura-projecta-complete-failure-jairam-ramesh/articleshow/12021823.cms

Rao, A. M., \& Rao, K. R. (2012). "Measuring Urban Traffic Congestion - a Review". International Journal for Traffic \& Transport Engineering, 2(4), 286-305.

Rapoport, A. (1985). "Uses of Experimental Games". In Grauer, M., Thompson, M., \& Wierzbicki, A. P. (Eds.), Plural Rationality and Interactive Decision Processes. Lecture Notes in Economics and Mathematical Systems (Vol. 248, pp. 147-161). Berlin, Heidelberg: Springer.

Riessman, C. K. (1993). Narrative Analysis. Newbury Park, Cal: Sage.

Roy, A. (2009). "Why India Cannot Plan Its Cities: Informality, Insurgence and the Idiom of Urbanization". Planning theory, 8(1), 76-87.

Russell, P. (2015). "The Emergence of Smart Cities". UT School of Architecture. Retrieved from https://sustainability.utexas.edu/sites/sustainability.utexas.edu/files/EmergenceofSmartCiti es_PatrickRussell.pdf.

Sarkar, A., \& Choudhury, S. (2014). Reasons for Low Employability of Engineering Graduates. Business Today (April 10, 2014).

Schaffers, H., Komninos, N., Pallot, M., Trousse, B., Nilsson, M., \& Oliveira, A. (2011). "Smart Cities and the Future Internet: Towards Cooperation Frameworks for Open Innovation". In J. Domingue et al. (Ed.), The Future Internet Assembly (pp. 431-446): Springer.

Schwarz, M., \& Thompson, M. (1990). Divided We Stand: Re-Defining Politics, Technology and Social Choice. Philadelphia: University of Pennsylvania Press.

Scott, J. W. (2007). "Smart Growth as Urban Reform: A Pragmatic'recoding'of the New Regionalism". Urban Studies, 44(1), 15-35.

Shapiro, J. M. (2005). "Smart Cities: Quality of Life, Productivity, and the Growth Effects of Human Capital". The Review of Economics and Statistics, 88(2), 324-335. 
Singh, N., \& Rao, G. (2006). Political Economy of Federalism in India. doi: 10.1093/acprof:oso/9780195686937.001.0001.

Stone, C. N. (1993). "Urban Regimes and the Capacity to Govern: A Political Economy Approach". Journal of Urban Affairs, 15(1), 1-28.

Stone, C. N., \& Sanders, H. T. (1987). The Politics of Urban Development. Lawrence: University Press of Kansas.

Thompson, M. (2008). Organising and Disorganising. A Dynamic and Non-Linear Theory of Institutional Emergence and Its Implication. Axminster: Triarchy Press.

Thompson, M., Ellis, R., \& Wildavsky, A. (1990). Cultural Theory. Boulder, Colorado: Westview Press.

Thompson, M., Rayner, S., \& Ney, S. (1998). "Risk and Governance Part Ii: Policy in a Complex and Plurally Perceived World". Government and Opposition, 33(3), 330-354.

Todes, A. (2011). "Reinventing Planning: Critical Reflections". Urban Forum, 22(2), $115-$ 133. doi: 10.1007/s12132-011-9109-x.

Townsend, A. M. (2013). Smart Cities: Big Data, Civic Hackers, and the Quest for a New Utopia. New York: WW Norton \& Company.

Tukahirwa, J. T., Mol, A. P., \& Oosterveer, P. (2010). "Civil Society Participation in Urban Sanitation and Solid Waste Management in Uganda". Local Environment, 15(1), 1-14.

Turner, M. A. (2007). "A Simple Theory of Smart Growth and Sprawl". Journal of Urban Economics, 61(1), 21-44.

Verweij, M., \& Thompson, M. (2006). Clumsy Solutions for a Complex World: Governance, Politics and Plural Perceptions. Basingstoke: Palgrave.

Ward, K. (1996). "Rereading Urban Regime Theory: A Sympathetic Critique". Geoforum, 27(4), 427-438. 